\title{
ASSESSING E-LEARNING ADOPTION IN NIGERIA UNIVERSITIES USING STUDENTS' PERSPECTIVE A CASE STUDY OF THE UNIVERSITY OF BENIN
}

FRANCISCA A. EGBOKHARE AND BERNADETTE I. IYAWE

(Received 30, May 2012; Revision Accepted 20, June 2012)

\begin{abstract}
It is an incentive that education has no age limit, which has made learning literarily a vital interest amidst all age groups. This paper explores the benefits of e-learning and examines a developing University's educational delivery and learning system to determine its position in global educational standards and technology utilization. The effectiveness of such level of Education is linked with four major interrelated factors - the learner (student), the teacher (lecturer), the Academic System (University Procedures) and the learning environment (local and national location). With the 'learner' often being the focus of any academic set up, the authors investigated students' perspectives of elearning and its access, using University of Benin as a case study. A sample population comprised students selected from three faculties in the University of Benin that offer Computer Science modules. The data collected was analyzed using quantitative approach. The findings revealed the major challenges to e-learning adoption as unavailable access to required infrastructures.
\end{abstract}

KEYWORDS: Learning, e-learning, classroom, ICT

\section{INTRODUCTION}

Learning has taken various dimensions since man's creation. Traditional teaching methods, where the teacher plays the role of the instructor, decision maker and shoulders the responsibility of classroom management are today giving way to alternative methods that encourage student-centered learning. Increased knowledge and diffusion of ICT in various sectors of the economy has necessitated huge investments and applications of its potentials in education and training. Electronic learning, 'the use of Internet technologies to deliver a broad array of solutions that enhance knowledge and performance' (Rosenberg, 2001), is swiftly gaining grounds in developed countries and gradually in developing countries as a combined method of online content delivery with conventional classroom delivery.

\section{E-LEARNING FOR DEVELOPING LEARNERS}

E-learning, which 'promotes learning through the delivery of instruction via a computer or the Web' (Clark and Mayer, 2003), is 'the use of network technology to design, deliver, select, administer, and extend learning' (The MASIE Center, 2011). Urdan and Weggen, 2000 extended the definition of e-learning as the delivery of content via all electronic media, including the Internet, intranets, extranets, satellite broadcast, audio/video tape, interactive TV, and CD-ROM'. E-learning is not limited to 'digital literacy' but may encompass multiple formats and hybrid methodologies that utilize electronic means of communication, education, and training to improve teaching and learning (Cedefop, 2002). The significant attributes of electronic or online learning that distinguishes it from traditional classroom learning are

Francisca A. Egbokhare, Department of Computer Science, Faculty of Physical Sciences, University of Benin, P.M.B 1154, Benin City, Nigeria.

Bernadette I. Iyawe, Department of Computer Science, Faculty of Physical Sciences, University of Benin, P.M.B 1154, Benin City, Nigeria. 
'convenience' and 'accessibility'. The significant benefit of this to a learner is being able to learn with everyone, every time and everywhere. Moreover, other benefits of e-learning include efficiency of information delivery (Rosenberg, 2001); flexibility since learning is learnercentered rather than teacher-centered (Van den Brande, 1993); learner responsibility since the learner is not a passive participant but a proactive searcher and finder of information (Block and Dobell, 1999); elimination of the expense and inconvenience of getting the instructor and students in the same place has triggered the adoption of e-learning as a more preferred learning approach than traditional classroom lectures (Bagui, 1998) as online interactions appear to have a strong positive effect on learning (Najjar, 1996).

With the improvement of teaching and learning resources, the extensive development of Instructional design has come to stay. In developing and developed countries, there is more or less a great deal of significant modern apparatus being used to share knowledge, construct and distribute learning. As the technological environment changes rapidly, it's important to reflect on the current state of technological-based education with regards to giving value to learning, precisely e-learning. Such steps being followed in developed countries depict the roll over from traditional classroom learning to web-based learning, which is sighted as a realizable dimension promoting Information Technology (IT) skills especially with the easy accessibility of the internet and contribution from networking concept. Now relatively all institutions or organizations provide some form of Internet access for implementation of virtual systems. For instance, the Open University, 2011, in UK is a convention towards the support of e-learning aimed at enabling especially adult learners and learners with learning difficulties to conquer their learning barriers.

Recently, there have been some encouraging e-learning attempts in some developing countries. Fernando, 2009 suggested certain activities that could be integrated into an e-learning system to make an impact in a University system, especially in the context of a third world country include: Curriculum related aspects -course contents; Discussions, library catalogues, etc.; Academic administration related aspects-registrations; Student information, grading, etc.; and Technology infrastructure related aspectsalternative. Mugarura, 2010 sighted the challenges of implementing a typical western elearning system at Makerere University, Uganda and suggests more ICT training for students and staff. Infrastructure, culture and previous knowledge have been reported as the most prominent barriers to the adoption of e-learning in most developing countries (Siavash et al., 2011). It is however vital to evaluate learners' perspective of e-learning, as a contribution to developing educational standards.

\section{RESEARCH METHODOLOGY}

This research study uses quantitative method and questionnaire that sought to address the following:

R1: Do UNIBEN students possess any knowledge in the use of computers and other forms of ICTs?

R2: E-learning requires anytime anywhere access to computer resources and the Internet. Are these facilities available to the students?

R3: Is there any form of online interaction between students and their lecturers?

R4: Who provides teaching and learning resources?

\section{Population}

Using random sampling, the sample population comprised first and second year undergraduate students selected from three Faculties offering Computer Science modules at the University of Benin.

\section{Data Collection}

Data was collected during the 2010/2011 academic session using questionnaire as major tool. The questions were structured in a manner that could enable the researchers elicit the necessary data to provide answers to the research questions. To ensure content validity and reliability, the questionnaire was tested on twenty (20) randomly selected students from the research sample. Issues raised relating to the complexity of the items was resolved before the final copies were prepared and distributed as email attachments to the students. 
Results, Findings and Discussions

A total of one thousand and twenty one $(1,021)$ completed questionnaires were returned. This high response rate was triggered by the students' good perceptions on the questionnaire's area of study. The study indicated that a large number of students are interested in using the internet and also granted some students the opportunity to participate in emailing system. Five hundred and eighty seven (587) questionnaires were used for the final data analysis with results presented in percentages and tables.

Table 1: Students' First Computer Knowledge Acquisition

\begin{tabular}{lll}
\hline & Frequency & Percentage (\%) \\
Primary School & 199 & 33.91 \\
Secondary School & 291 & 49.57 \\
University & 58 & 9.88 \\
Others & 39 & 6.64 \\
\hline
\end{tabular}

Table 2: E-learning Infrastructure/Adoption Level in the University of Benin

\begin{tabular}{lll}
\hline & $\begin{array}{l}\text { Frequency((\%)) } \\
\text { Yes }\end{array}$ & $\begin{array}{l}\text { Frequency((\%)) } \\
\text { No }\end{array}$ \\
University's provision of Computer access Facilities: & $196(33.39)$ & $391(66.61)$ \\
University's provision of facilities for Internet access: & $0(0)$ & $587(100)$ \\
Interest in Computer/Internet training if provided by Institution: & $563(95.91)$ & $24(4.09)$ \\
Private access to computers: & $92(15.67)$ & $495(84.33)$ \\
Private access to Internet: & $159(27.09)$ & $428(72.91)$ \\
Awareness of e-learning/other related online learning activities: & $291(49.57)$ & $296(50.43)$ \\
Online Communication between Student and Lecturer: & $145(24.70)$ & $442(75.30)$ \\
\hline
\end{tabular}

Table 3: Provision of Learning and Delivery Resources

\begin{tabular}{lll}
\hline & Frequency & Percentage (\%) \\
University & 392 & 66.78 \\
Government & 122 & 20.78 \\
Personal & 25 & 4.26 \\
Class Contribution & 36 & 6.14 \\
Other & 12 & 2.04 \\
\hline
\end{tabular}

Table 4: Students' Preferred Learning Method

\begin{tabular}{lll}
\hline & Frequency & Percentage (\%) \\
Online & 227 & 38.67 \\
Classroom & 360 & 61.33 \\
\hline
\end{tabular}


Table 1 retorts research question 1 (R1) and reveals that though adoption of e-learning is not limited to possession of some form of digital or computer literacy, it is one of the basic requirements in pre-university education, as most of the students already had prior knowledge about computers from primary (33.91\%) and secondary school (49.57\%). This may be as a result of the integration of 'Introduction of Computer Science' as a subject into the Primary, Junior and Secondary Schools Curriculum in Nigeria (Jegede and Owolabi, 2003). E-learning requires unlimited access to computers and other Internet resources. Thus, to answer research question 2 (R2), we elicited information on the infrastructure/computer facilities available to the students. Students that offer Computer Science modules are expected to use Computer facilities provided by the University for practical knowledge acquisition sessions. The results from Table 2 however show that less than half of the students $(33.39 \%)$ have access to the Computer laboratories provided by the University and $15.67 \%$ have private access to computers. Also, in terms of Internet access, none of the respondents $(0 \%)$ have access to Internet facilities provided by the Institution, though $27.09 \%$ have private Internet access. At late 2011 a partnership commenced between Google and the University of Benin for the provision of hot spots within the University's campus for students' Internet access. However, this research finding shows that there is still low overall computer/Internet access by the respondents, since Computers and the Internet are the major drivers of e-learning. One of the factors that distinguish e-learning from traditional learning is accessibility, which makes the learner proactive and eager to seek and exploit new ideas.

As seen in Table 2 about half of the respondents $(49.57 \%)$ are aware of e-learning and other related online activities, and $95.91 \%$ are interested in more basic or intricate computer/Internet training. This finding further buttressed the suggestion by Mugarura (2010) that apart from infrastructural challenges, more computer and Internet training may be required by students and staff in developing countries before investing in e-learning technologies. Elearning is conceived as a convenient method of content dissemination since the teacher and learner can be geographically apart while learning is effectively achieved via online interactions. Thus, to determine the level of elearning adoption in the University of Benin, research question 3 (R3) sought to gain insight to the level of online interaction between students and lecturers. The distribution of the research questionnaires via e-mail attachments was to determine how often students accessed their mail boxes and how prompt they could respond to online instructions. However, only $24.70 \%$ of students interact with their lecturers online as revealed in Table 2 . The teaching/learning method adopted by an institution is determined to a large extent by the type of learning resources provided. Though elearning promises several gains to both the instructor and learner, appropriate recommendations can only be implemented if the stakeholders are identified and key research findings are directed to them. Thus the main aim of research question 4 (R4) is to identify who, in the respondents' opinion should provide the necessary infrastructure for e-learning. The results in Table 3 showed that it is the responsibility of the University $(66.78 \%)$ and the Government (20.78\%) to create a global standard environment for teaching and learning by providing the required resources. Since the $2002 / 2003$ academic session, the University of Benin has made several attempts to introduce the use of various forms of ICTs in academic administration and student information systems. These include online course application/registration, online hostel allocation and school fees payment via the Institution's portal, introduction of a digital library, communication of campus news/other relevant information to students via the University's website, etc. The findings from this study indicate the existence of infrastructural challenges especially in the area of using ICTs for content production and delivery.

Moreover, the high response rate (95.91\%) from Table 2 regarding training interest in Computer and Internet usage shows an urgent need to provide enthusiastic hands-on training for students on the basics of Computer and Internet usage. To conclude the study, we asked respondents to choose the most preferred learning method. Majority $(61.33 \%)$ preferred the traditional classroom method as revealed in Table 4. This high response is however influenced by the consistent teaching/learning cultures that the students have been exposed to. 


\section{CONCLUSION}

With the tremendous benefits e-learning offers, it is detrimental that some learners are not opportune to extensively explore these benefits and instead mostly engage in traditional classroom delivery such as in University of Benin. As a result, this may further widen the knowledge and education quality distinction rendered between learners in developed and developing nations, if adequate measures are not taken. Provision of necessary e-learning infrastructure and proper ICT training would be of immense benefits to the learners not only for their learning development but also career pursuits. ICT has become a global language in today's economy and it is expected that there be a paradigm shift in Nigeria's educational system.

\section{RECOMMENDATION}

Developing Universities in addition to the student online registration portal and computer rooms, require sustainable channels for virtual learning environments, precisely e-learning, and adoption of standardized educational and Information Technology trends such as those in developed environments. It is academically rewarding to establish a comprehensive and consistent e-learning framework (learning off campus via web) that would enable the provision of distance learning and welcome International learners from developed countries, as some developing Universities are equipped with professionals and scholars in various research areas. More so, extensive investment in courseware and e-learning facilities, organization of staff training for content upload and delivery, substantial and effective partnership with elearning providers, Mobile/Wireless Telecommunication Network companies, private and public partnership in realizing these integrations are majorly required. Such actions can eventually open doors for a progressive Nigeria Academics, inflate inventions by young researchers, and further improve learners' perspective of e-learning, teaching and learning quality.

\section{REFERENCES}

Bagui, S., 1998. Reasons for Increased Learning using Multimedia. Journal of Educational Multimedia and Hypermedia., 7: 3-18.
Block, H. and Dobell, B., 1999. The e-Bang Theory: Education Industry Overview, In Equity Research, Volume 2. Bank of America Securities, Montgomery Division, San Francisco CA, Illuminismo.

CEDEFOP, 2002. E-Learning and Training in Europe - A Survey in to the use of ELearning in Training and Professional Development in the European Union. In The European Centre for the Development of Vocational Training, Reference Series: 26. Greece.

Clark, R. C. and Mayer, R. E., 2003. E-Learning and the Science of Instruction. CA: Pfeiffer, Wiley Imprint.

Fernando, S., 2009. Issues of E-Learning in Third World Countries. IT Education, pp. $2273-2274$.

Jegede, P. O. and Owolabi, J. A., 2003. Computer Education in Nigerian Secondary Schools Gaps between Policy and Practice, Meridian: A Middle School Computer Technologies Journal. 6 (2). Retrieved March 6, 2012 from: http://www.ncsu.edu/meridian/sa,2003 /nigeria/index.html

MASIE Center Learning TRENDS, 2011. Retrieved May 2, 2011 from: http://www.masie.com

Mugarura, C., 2010. Strategies for Deploying eLearning in Developing Countries. In eLearning Promise: Educational Technology Debate: Exploring ICT and Learning in Developing Countries. Retrieved May 2, 2011 from: https://edutechdebate.org/elearningpromise/strategies-for-deployingelearning-in-developing-countries

Najjar, L. J., 1996. Multimedia Information and Learning. Journal of Educational Multimedia and Hypermedia 5 (2): 129150.

Rosenberg, M. J., 2001. E-Learning: Strategies for Delivering Knowledge in the Digital Age. New York: McGraw-Hill. 
Siavash, O., Maslin, M., and Harihuddin, S., 2011. Review of E-Learning and ICT Infrastructure in Developing Countries Case Study of Iran. American Journal of Economics and Business Administration 3(1): $120-125$.
The Open University. 2011. Retrieved May 2, 2011 from: http://www.open.ac.uk/

Urdan, T. A. and Weggen. C. C., 2000. Corporate E-Learning: Exploring a New Frontier. W R Hambrecht and Co.

Van Den Brande, L., 1993. Flexible and Distance Learning. Chichester, UK: John Wiley. 